\title{
TROCAS GASOSAS E EFICIÊNCIA FOTOQUÍMICA POTENCIAL EM MAMOEIRO DO GRUPO ‘FORMOSA’ CULTIVADO EM CONDIÇÃO DE CAMPO $\left({ }^{1}\right)$
}

\author{
FABRÍCIO DE OLIVEIRA REIS $\left(2^{*}\right)$; ELIEMAR CAMPOSTRINI $\left({ }^{3}\right)$
}

\begin{abstract}
RESUMO
Em mamoeiro, estudar como os fatores do ambiente afetam as trocas gasosas é de fundamental importância para otimizar a assimilação fotossintética do carbono e do controle da perda de água. Para tanto, em duas épocas, outubro de 2002 e janeiro de 2003, foram estudadas as trocas gasosas e a eficiência fotoquímica potencial em mamoeiros do grupo 'Formosa', cultivados em condição de campo em São Francisco de Itabapoana (RJ). As determinações das características estudadas, como Assimilação fotossintética de $\mathrm{CO}_{2}(A)$, densidade de fluxo de fótons fotossintéticos (DFFF) e condutância estomática $\left(\mathrm{g}_{\mathrm{S}}\right)$ foram feitas diariamente, em quatro dias de cada mês, a cada 1 hora, no período de 8 as 17 h. Em adição, foram efetuadas as medidas da eficiência fotoquímica potencial nas mesmas folhas e mesmo horário em que foram realizadas as determinações das trocas gasosas. A assimilação fotossintética de $\mathrm{CO}_{2}$ foi maior em janeiro. Tal resultado foi devido à maior abertura estomática nas folhas das plantas cultivadas nesta época. A menor assimilação fotossintética de $\mathrm{CO}_{2}$ em outubro, causada pela redução de $\mathrm{g}_{\mathrm{S}}$, foi decorrente da maior densidade de fluxo de fótons fotossintéticos (dias com ausência de nuvens) verificado em outubro. Nas condições em estudo, por meio de medições da eficiência fotoquímica potencial, não foi verificado o efeito fotoinibitório do tipo crônico. É possível que esta não-detecção do dano ao aparato fotossintético tenha sido causada pelo movimento paraeliotrópico das folhas, observado nos horários mais quentes do dia. Estes resultados podem contribuir significativamente no manejo da cultura do mamoeiro cultivado em condição de campo, uma vez que qualquer estratégia de manejo que possa otimizar a abertura estomática trará contribuições para a assimilação fotossintética de $\mathrm{CO}_{2}$, com possibilidades de aumento de produtividade.
\end{abstract}

Palavras-chave: Carica papaya L., trocas gasosas, eficiência fotoquímica.

\section{ABSTRACT \\ LEAF GAS EXCHANGE AND POTENTIAL PHOTOCHEMICAL EFFICIENCY OF FIELD-GROWN PAPAYA PLANTS}

A real understanding of how the environmental factors affect gas exchange is extremely important for the optimization of $\mathrm{CO}_{2}$ photosynthetic assimilation and water loss control. In order to contribute to this, in two seasons, October 2002 and January 2003, the gas exchange and the potential photochemical efficiency in 'Formosa' papaya plants cultivated under field condition in São Francisco do Itabapoana, Rio de Janeiro State, were studied. The $\mathrm{CO}_{2}$ photosynthetic assimilation $(A)$, stomatal conductance $\left(\mathrm{g}_{\mathrm{S}}\right)$, photosynthetic photon flux density (PPFD) were evaluated daily, four days per month, each every hour, from 8 a.m. to 5 p.m. In addition, the potential photochemical efficiency was measured from the same leaves and at the same conditions as before. The $\mathrm{CO}_{2}$ photosynthetic assimilation was higher in January. This result was due to a greater stomatal aperture on leaves of plants cultivated during this season. The lower $A$ value observed in October, caused by the reduction of $g_{S}$, was due to a higher photosynthetic photon flux density (Cloudless days) occurred in this month. Under the experimental conditions, measuring the potential photochemical efficiency, the photoinhibitory chronic type effect was not verified. Possibly the non-detection of damage to the photosynthetic apparatus has been due to the paraheliotropic movement of leaves, observed at warmer periods of the day. These results can contribute significantly for the papaya tree management grown under field condition, since any management strategy that optimizes the stomatal aperture will help the $\mathrm{CO}_{2}$ photosynthetic assimilation, and may result in an increase of productivity.

Key words: Carica papaya L., gas exchange, photochemical efficiency.

$\left({ }^{1}\right)$ Recebido para publicação em 17 de maio de 2006 e aceito em 10 de junho de 2008.

$\left(^{2}\right)$ Departamento de Biologia Vegetal-Botânica, Universidade Federal do Espírito Santo, Avenida Fernando Ferrari, 514, 29075-910 Vitória (ES). E-mail: fareoli@gmail.com $\left(^{*}\right)$ Autor correspondente.

$\left({ }^{3}\right)$ Setor de Fisiologia Vegetal, Universidade Estadual do Norte Fluminense, Centro de Ciências e Tecnologias Agropecuárias, Avenida Alberto Lamego, 2000, 28015-620 Campos dos Goytacazes (RJ). E-mail: campost@uenf.br 


\section{INTRODUÇÃO}

O entendimento da contribuição dos efeitos estomáticos e os não-estomáticos sobre o processo de assimilação do carbono em Carica papaya L. é muito importante para se traçar estratégias de manejo em plantios comerciais desta espécie. Dessa maneira, o entendimento de como os fatores do ambiente influenciam a assimilação fotossintética de $\mathrm{CO}_{2}(A)$ torna-se muito importante, uma vez que a otimização dos tais fatores pode propiciar elevações nos valores de $A$ e, possivelmente, contribuir para o aumento da produtividade do mamoeiro. Além de possíveis aumentos na produtividade, o aumento na assimilação fotossintética do carbono pode contribuir significativamente na qualidade dos frutos em mamoeiro (SALAZAR,1978). Porém, as alterações na assimilação fotossintética de $\mathrm{CO}_{2}$ não estão somente associadas aos efeitos estomáticos. Em algumas situações, os fatores não-estomáticos podem ter uma importante influência sobre a regulação de $A$ durante o dia (Xu e SHen, 1997).

O mamoeiro (Carica papaya L.) é considerado uma planta herbácea de grande porte (Malo e CAMPBell, 1986), possuindo essa espécie considerável sensibilidade às variáveis atmosféricas como temperatura, luz e déficit de pressão de vapor (ELSharkawy et al., 1985; Marler e Mickelbart, 1998; Machado FilHo et al. 2006). No trabalho desenvolvido por MACHADO FilHo et al. (2006), no Sudoeste da Bahia, a assimilação fotossintética de $\mathrm{CO}_{2}(A)$ foi dependente da condutância estomática $\left(g_{\mathrm{S}}\right)$, e os valores de $\mathrm{g}_{\mathrm{S}}$ foram maiores nos meses com menor DPV do ar. Estas informações revelaram a elevada relação negativa entre o $D P V_{a r}$ e g nesta espécie. Resultados semelhantes foram observados por EL-SHARKAWY et al. (1985). Segundo esses autores, a espécie Carica papaya foi responsiva ao $\mathrm{DPV}_{\text {folha-ar. }}$

A perda de água das folhas é controlada, de maneira geral, pelo déficit de pressão de vapor entre a folha e o ar $\left(\mathrm{DPV}_{\text {folha-ar }}\right)$. A assimilação fotossintética de $\mathrm{CO}_{2}$ é elevada em umidades mais altas e, freqüentemente, observa-se que na condição de reduzidos valores de $D P V_{\text {folha-ar, }}$ a condutância estomática $\left(\mathrm{g}_{\mathrm{S}}\right)$ também é elevada. As condições de baixa umidade podem causar excessivas perdas de água; nas folhas pode ocorrer considerável fechamento estomático e afetar significativamente as trocas de dióxido de carbono entre esses órgãos e o ar.

Embora a luz seja a fonte de energia para o processo fotossintético e, obviamente, o pré-requisito essencial para a vida na Terra, o excesso desse recurso pode ter como conseqüência a redução ou mesmo a inibição da assimilação fotossintética de $\mathrm{CO}_{2}$ (LONG et al., 1994). O excesso de luz pode causar uma destruição fotooxidativa do aparato fotossintético (Demmig-Adams e Adams III, 1992), ou seja, nessa condição, a energia luminosa não é utilizada no processo fotossintético. Este processo de diminuição da eficiência na incorporação do carbono pela elevada energia luminosa é denominado fotoinibição (Long et al., 1994) e pode ocorrer em condições de campo na ausência de qualquer outro tipo de estresse (ÖGreEn, 1988). O processo fotoinibitório é sempre caracterizado por redução no rendimento quântico do fotossistema II (CRITCHLEY e RUSSELL, 1994), redução no rendimento quântico da fotossíntese quando avaliada pela absorção de $\mathrm{CO}_{2}(\phi)$ e liberação de $\mathrm{O}_{2}\left(\phi_{0}\right)$ (LONG et al., 1994); freqüentemente, observa-se significativo decréscimo em $A$ em fluxo de fótons fotossintético saturantes em folhas e em cloroplastos isolados (Powles e Critchley, 1980). Uma vez que os decréscimos nos rendimentos quânticos $\phi$ e $\phi_{0}$ estão correlacionados com o decréscimo nos valores do rendimento quântico máximo do PSII (caracterizado pelos reduzidos valores da relação $\left.F_{V} / F_{M}\right)$, as hipóteses fortalecem que o dano causado por excesso de luz esteja atuando no PSII (LoNG et al., 1994).

Apesar de o excesso de luz causar comprometimentos no processo fotossintético, durante o processo evolutivo, as plantas possuem mecanismos para evitar o dano fotoinibitório. Segundo Long et al. (1994), os mecanismos pelos quais as plantas evitam este dano podem ser de fatores externos e internos. Os fatores externos são responsáveis pelo decréscimo físico da absorção de luz, ou seja, as plantas desenvolvem mecanismos para evitar a exposição acentuada da radiação luminosa. Esses fatores externos podem ser relatados como a acentuada capacidade de reflexão da luz pela cutícula (ROBINSON et al, 1993), os movimentos dos cloroplastos (BRUGNOLI e BJÖRKMAN, 1992), a síntese e deposição de pigmentos não-fotossintéticos, como as antocianinas na epiderme superior da folha (LonG, 1983) e os movimentos paraeliotrópicos (LudLOW e BJÖRKMAN, 1984; KAO e FORSETH, 1992).

Com relação aos últimos mecanismos, nas situações de elevados valores de densidade de fluxo de fótons fotossintéticos (DFFF), as folhas das plantas se mantêm paralelas em relação aos raios solares. Nessa condição, ocorre uma minimização da absorção direta da energia luminosa (Long et al., 1994). Contudo, em algumas plantas, estas folhas ficam perpendiculares aos raios solares (movimento diaeliotrópicos) na parte da manhã e na parte da tarde (KAO e Forseth, 1992). Entretanto, segundo estes autores, em torno do meio-dia, a resposta é paraeliotrópica. Esses padrões nas alterações no movimento foliar em relação à luz maximizam a 
interceptação quando a luz é limitante; minimizam a interceptação da luz quando este fator está em excesso (Long et al., 1994; ReIs, 2003). Segundo Gamon e Pearcy (1998), o movimento paraeliotrópico possui a capacidade de evitar a elevação da temperatura foliar, além do controle da fotoinibição.

O objetivo do presente trabalho foi caracterizar em duas épocas de cultivo as trocas gasosas e a eficiência fotoquímica em mamoeiros do grupo 'Formosa', cultivados em condição de campo.

\section{MATERIAL E MÉTODOS}

\section{Material vegetal e condições de cultivo}

Foram efetuados estudos em uma área de plantio comercial de mamoeiro do grupo 'Formosa', localizado no município de São Francisco de Itabapoana (RJ), em latitude de $21^{\circ} 27^{\prime} \mathrm{S}$, longitude de $41^{\circ} 15^{\prime} \mathrm{O}$ e com altitude de $12 \mathrm{~m}$ acima do nível do mar. A área escolhida localizava-se em Argissolo Amarelo, com cerca de 40 ha e relevo suave ondulado. Nesse local, foram utilizadas plantas de mamoeiro (Carica papaya L.) do grupo 'Formosa' e as medições das características estudadas foram feitas em outubro de 2002 e janeiro de 2003 (plantas com 9 e 12 meses de idade respectivamente). A lavoura foi irrigada com o sistema do tipo pivô central, não havendo turno de rega definido. O espaçamento utilizado foi de $3,8 \times$ $2,0 \mathrm{~m}$, totalizando uma densidade de 1.316 plantas $\mathrm{ha}^{-1}$. Este manejo foi adotado pelo produtor para a produção comercial de frutos.

\section{Variáveis meteorológicas e tensão de água no solo}

As variáveis do ambiente como temperatura, umidade relativa e tensão de água no solo foram monitoradas por meio de sensores automáticos de coleta de dados (Loggers) modelo WatchDog 450 (Spectrum Technologies, Illinois, E.U.A.) Os dados foram armazenados a cada 1 hora. Os sensores de umidade do solo foram colocados a uma profundidade de $0,30 \mathrm{~m}$, e $0,40 \mathrm{~m}$ de distância do tronco. Ao todo, foram utilizados quatro sensores (dois sensores por planta).

Em outubro de 2002, a temperatura média mensal foi de $29,4 \pm 2,7^{\circ} \mathrm{C}$, a umidade relativa foi de $48,3 \pm 9,7 \%$ e o $\mathrm{DPV}_{\text {ar }}$ foi de $2,2 \pm 0,7 \mathrm{kPa}$. Em janeiro de 2003, a temperatura média mensal foi de $29,9 \pm 2,7$ ${ }^{\circ} \mathrm{C}$, a umidade relativa foi de $68,5 \pm 11,15 \%$ e o $\mathrm{DPV}_{\mathrm{ar}}$ foi de 1,4 $\pm 0,7 \mathrm{kPa}$.

A tensão de água no solo média $28,5 \pm 8 \mathrm{kPa}$ e $12,1 \pm 8,7 \mathrm{kPa}$ em outubro de 2002 e janeiro de 2003 respectivamente.

\section{Determinação das trocas gasosas}

As avaliações da assimilação fotossintética de carbono $\left(A, \mu \mathrm{mol} \mathrm{m} \mathrm{m}^{-2} \mathrm{~s}^{-1}\right)$, densidade fluxo de fótons fotossintéticos (DFFF, $\mu \mathrm{mol} \mathrm{m} \mathrm{m}^{-2} \mathrm{~s}^{-1}$ ), e da condutância estomática $\left(g_{\mathrm{S}}, \mathrm{mol} \mathrm{m}^{-2} \mathrm{~s}^{-1}\right)$ foram feitas por meio do sistema portátil de medições de trocas gasosas, modelo LI-6200 (LI-COR, Lincoln, NE, USA). Em outubro, para a determinação das trocas gasosas, foram utilizadas 12 plantas escolhidas aleatoriamente na área de plantio. Em janeiro, foram escolhidas oito plantas. Em outubro, as avaliações foram feitas em seis dias de medições e em janeiro, as avaliações foram feitas em quatro dias. Nas épocas estudadas, em cada dia, as avaliações das trocas gasosas foram feitas em duas plantas. Essas determinações foram feitas a cada 1 hora no período das 8 às $17 \mathrm{~h}$. Em cada planta, foram utilizadas duas folhas crescidas em pleno sol $\left(9 .^{\mathrm{a}} \mathrm{e} 10{ }^{\mathrm{a}}\right.$ folhas contadas a partir do ápice) para as determinações.

\section{Determinação da eficiência fotoquímica potencial e do Î́ndice SPAD-502}

No mesmo local da folha, dia e horário em que se determinaram as trocas gasosas, foram feitas as medições da fluorescência com o auxílio do fluorômetro modelo MINI-PAM (Walz, Alemanha). Foram efetuadas as medidas da relação $\mathrm{F}_{\mathrm{V}} / \mathrm{F}_{\mathrm{M}}$. Para tanto, antes das determinações das variáveis da fluorescência, a área em que foi determinada esta variável, foi mantida no escuro durante 30 minutos, por meio de pinças, para que os centros de reação adquirissem a condição de "abertos", ou seja, todo o sistema estivesse no estado oxidado.

A estimativa do conteúdo de clorofila foi avaliada por meio dos valores do índice de SPAD-502 e foi feita em cada folha e em cada época de medição das trocas gasosas por meio do medidor portátil de clorofila (MPC), SPAD-502 (Minolta, Japão). Estas determinações, 10 medições por folha, foram feitas nas mesmas folhas onde se fizeram as medições das trocas gasosas e da eficiência fotoquímica potencial. Os valores de SPAD variaram entre 45 e 55 nas duas épocas estudadas. Estes valores revelam ótima disponibilidade de $\mathrm{N}$ no tecido foliar, bem como excelente quantidade de pigmentos fotossintéticos (Torres-Netto et al, 2002).

\section{RESULTADOS E DISCUSSÃO}

Em outubro de 2002, durante os dias de medições das características estudadas, a densidade de fluxo de fótons fotossintéticos variou de $190 \mu \mathrm{mol} \mathrm{m}{ }^{-2}$ $\mathrm{s}^{-1}(17 \mathrm{~h})$ a $1877 \mu \mathrm{mol} \mathrm{m} \mathrm{m}^{-2} \mathrm{~s}^{-1}(11 \mathrm{~h})$, estando o céu praticamente sem nuvens, nos primeiros 20 dias do mês. 
Entretanto, janeiro de 2003 se caracterizou pela considerável porcentagem de nuvens no céu. Embora em janeiro tenha ocorrido DFFF máxima maior do que em outubro (2.393 $\mu \mathrm{mol} \mathrm{m}^{-2} \mathrm{~s}^{-1}$ ao meio dia), a DFFF mínima nesta época foi menor do que em outubro de $2002\left(151 \mu \mathrm{mol} \mathrm{m} \mathrm{m}^{-2} \mathrm{~s}^{-1}\right.$ às $\left.16 \mathrm{~h}\right)$ e a variação ao longo do dia foi maior do que em janeiro. De fato, janeiro foi uma época mais chuvosa, comparando com outubro de 2002, justificando a maior presença de nuvens, o que veio contribuir também na elevação da umidade relativa do ar $(68,5 \pm 11,15)$ e da melhora da disponibilidade hídrica do solo $(12,1 \mathrm{kPa} \pm 8,7)$.

Embora Clemente e Marler (1996) tenham relatado que os estômatos do mamoeiro sejam responsivos à variação de DFFF, no presente trabalho essa relação não foi muito clara (dados não mostrados). Esse processo revela que nos meses estudados, a densidade de fluxo de fótons fotossintéticos (DFFF) não foi o principal fator na variação da condutância estomática $\left(\mathrm{g}_{\mathrm{S}}\right)$. Segundo PeArCy (1998), as folhas crescidas em pleno sol estão sujeitas às variações no DFFF e requerem ajustes nas respostas fotossintéticas para otimizar a eficiência deste processo. Pearcy (1998) acrescenta que tais ajustes ocorrem em períodos de segundos ou dias, e relacionam-se à ativação de enzimas do processo fotossintético, à regulação estomática e aos mecanismos de dissipação do excesso da energia luminosa.

Na figura 1 , observa-se em outubro, às $8 \mathrm{~h}$, os valores de $g_{S}$ foram em torno de $0,30 \mathrm{~mol} \mathrm{~m}^{-2} \mathrm{~s}^{-1}$, tendo uma queda a partir deste horário até às $14 \mathrm{~h}$, quando houve uma recuperação até às $17 \mathrm{~h}$ com valor em torno de $0,28 \mathrm{~mol} \mathrm{~m}^{-2} \mathrm{~s}^{-1}$. Já em janeiro de 2003 , às $8 \mathrm{~h}$, o valor de $\mathrm{g}_{\mathrm{S}}$ foi de ,aproximadamente, $0,70 \mathrm{~mol} \mathrm{~m}^{-2} \mathrm{~s}^{-1}$ com redução até às $12 \mathrm{~h}$, e condutância estomática de $0,40 \mathrm{~mol} \mathrm{~m}^{-2} \mathrm{~s}^{-1}$; esse valor foi mantido até às $17 \mathrm{~h}$. Em outubro, durante todo o dia, a condutância estomática foi menor que em janeiro (Figura 1). De fato, outubro caracterizou-se por umidade relativa $(48,3 \%$ $\pm 9,7)$ e disponibilidade hídrica do solo $(28,5 \mathrm{kPa} \pm 8,5)$, menor que em janeiro (umidade relativa de $68,5 \% \pm$ $11,15$ e tensão de água no solo de $12,1 \mathrm{kPa} \pm 8,7)$. Dessa forma, o DPV ar em outubro $(2,2 \mathrm{kPa} \pm 0,7)$ foi maior do que em janeiro $(1,4 \mathrm{kPa} \pm 0,7)$. Porém, as temperaturas médias do ar nos dois meses em estudo foram bem próximas $\left(29,4{ }^{\circ} \mathrm{C} \pm 2,7\right.$ em outubro e 29,9 ${ }^{\circ} \mathrm{C} \pm 2,6$ em janeiro). Em outubro, durante todas as medidas, o céu estava sem nuvens. Esse fato revela que maior quantidade de luz chegou até a folha e pode ter promovido maior ação desta variável sobre o $\mathrm{DPV}_{\text {folha-ar, }}$ influenciando negativamente sobre a condutância estomática.

$\mathrm{Na}$ literatura, vários trabalhos relatam os efeitos negativos do $\mathrm{DPV}_{\text {folha-ar }}$ sobre a condutância estomática (EL-SHARKAWY e COCK, 1984, El-SHARKAWY et al., 1985, MonTeITH, 1995). Uma justificativa para tal resposta pode ser decorrente do maior $\mathrm{DPV}_{\mathrm{ar}}$ em outubro, quando comparado a janeiro. Ou seja, a maior demanda hídrica da atmosfera, avaliada pelo maior valor de $\mathrm{DPV}_{\text {ar }}$ pode ter promovido perda de água das células estomáticas para o ar externo a estas células, fenômeno conhecido como evaporação periestomática (MAIER-MAERCKer, 1983). Em mamoeiro cultivado no cerrado baiano, em relação a novembro e dezembro $(» 1,25 \mathrm{kPa}$ as $15: 00)$, o elevado déficit de pressão de vapor do ar (»2,6kPa as 15:00), verificado em julho e setembro (época seca) causou fechamento estomático, em dois genótipos de mamoeiro (Tainung e Sunrise Solo), o que contribuiu para a redução nos valores da assimilação fotossintética de $\mathrm{CO}_{2}$. Neste estudo, foi verificado que a resposta foi semelhante nos dois genótipos estudados e, na época seca, o fechamento estomático causou elevação na eficiência intrínseca no uso da água (MAchado FilHo et al., 2006).

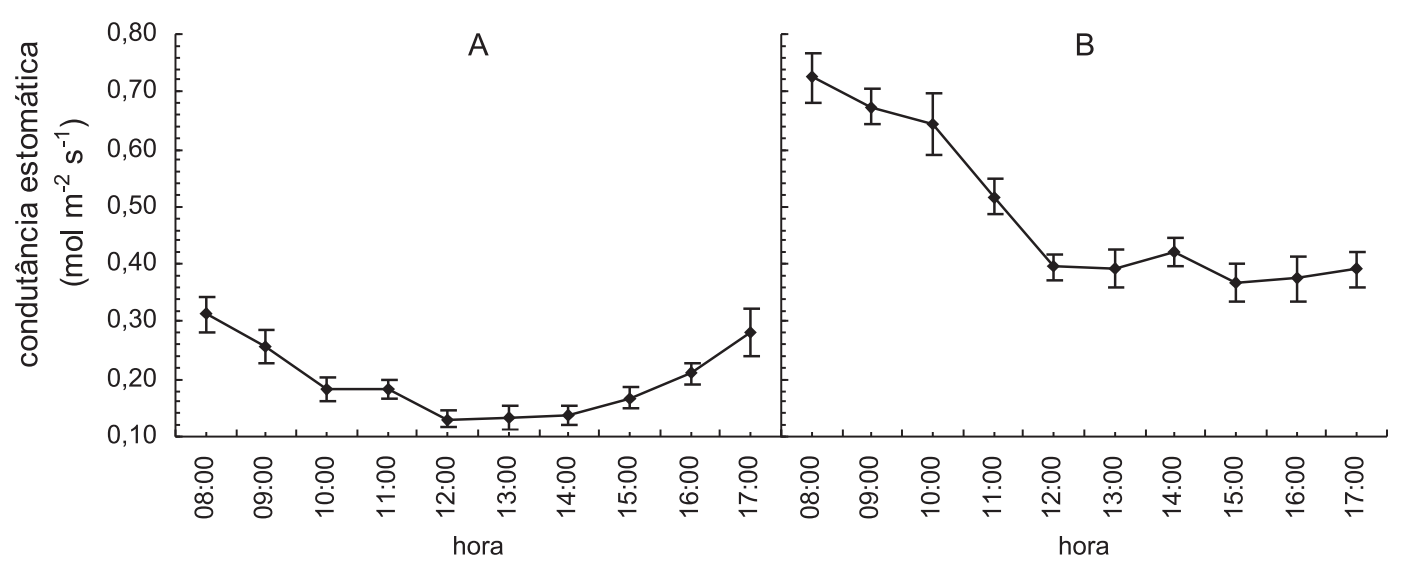

Figura 1. Variação da condutância estomática ao longo do dia em outubro de 2002 (A) e em janeiro de 2003 (B). As barras verticais indicam o erro-padrão. 
Elevados valores de DPV $\mathrm{V}_{\text {folha-ar }}$ podem causar reduções significativas na condutância estomática e, conseqüentemente, no processo fotossintético (ELSHARKAWY et al, 1985) no mamoeiro. Nessa espécie, esses autores relataram que houve redução de $47 \%$ e $48 \%$ na condutância estomática e na taxa fotossintética líquida, respectivamente, quando o $\mathrm{DPV}_{\text {folha-ar }}$ variou de 1 a 1,5 $\mathrm{kPa}$ para 3,5 a 4,5 kPa. Segundo os mesmos autores, em 19 espécies estudadas, incluindo a espécie Carica papaya L., o fechamento estomático causado pelo DPV folha-ar pode estar relacionado com a evaporação periestomática, ou seja, saída da molécula de água diretamente das células-guarda para o meio externo da folha.

Marler e Mickelbart (1998) obtiveram resultados semelhantes, evidenciando que o padrão diurno das trocas gasosas em mamoeiros cultivados sob condição de campo é dependente das condições climáticas e, sob condição de céu com ausência de nuvens, o DPV do ar pode afetar significativamente os valores de A, por meio da redução de $\mathrm{g}_{\mathrm{S}}$. Esse fato não é observado nos dias nublados.

Na figura 2, observa-se a variação de $A$ ao longo do dia, e em ambas as épocas houve um padrão de comportamento semelhante ao da condutância estomática. Em outubro (figura $2 \mathrm{~A}$ ), às $8 \mathrm{~h}, A$ apresentou o valor em torno de $12 \mu \mathrm{mol} \mathrm{m} \mathrm{m}^{-2} \mathrm{~s}^{-1}$, seguida de um redução nesses valores até o meio dia, com um valor em torno de $6 \mu \mathrm{mol} \mathrm{m}^{-2} \mathrm{~s}^{-1}$. Após às 14 $\mathrm{h}$, houve uma pequena recuperação da assimilação de carbono. Por esses dados, constatou-se dependência da assimilação fotossintética de $\mathrm{CO}_{2}$ com $\mathrm{g}_{\mathrm{S}}$, tanto no mês de outubro quanto em janeiro de 2003.

$\mathrm{Na}$ figura 2B, em janeiro, os valores de $A$ foram maiores, com valores iniciais por volta de 16 $\mu \mathrm{mol} \mathrm{m} \mathrm{s}^{-2} \mathrm{~s}^{-1}$, e aumento às $10 \mathrm{~h}$ e $11 \mathrm{~h}$, com valores próximos a $20 \mu \mathrm{mol} \mathrm{m} \mathrm{m}^{-2} \mathrm{~s}^{-1}$. A partir das $11 \mathrm{~h}$, há redução dos valores de $A$ até o horário de meio- dia, quando houve permanência dos valores em torno de $14 \mu \mathrm{mol} \mathrm{m}{ }^{-2} \mathrm{~s}^{-1}$ até às 15 horas, e uma ligeira recuperação às $16 \mathrm{~h}$. Houve uma nova redução às $17 \mathrm{~h}$.

Este padrão de resposta de queda dos valores de $A$, observado em ambas as épocas estudadas, é um fenômeno que ocorre na maioria das plantas de clima tropical. Esse fenômeno é chamado de depressão da fotossíntese ao meio-dia (DFMD), e ocorre nos horários mais quentes do dia. A DFMD pode reduzir drasticamente a assimilação de carbono, por meio da redução na condutância estomática (RASCHKE e Rosemann, 1986; Chaumont et al., 1997; Su e Liu, 2005; REIS, 2007). Na literatura, tem-se relatado que a DFMD é causada por fatores estomáticos e não-estomáticos (Xu e Shen, 1997; Huang et al., 2006).

Apesar de o processo fotoinibitório ocorrer em condições de campo (ÖGrEEN, 1994), em algumas plantas, cultivadas nestas condições, podem ser verificados mecanismos para que o processo fotossintético não seja comprometido pelo excesso de energia solar. Em videiras, CHAUmont et al. (1997) verificaram que a redução do processo fotossintético ao meio-dia não foi causada pela fotoinibição. No relato desses autores, verifica-se que os efeitos estomáticos foram os principais responsáveis pelo decréscimo nos valores da assimilação fotossintética de $\mathrm{CO}_{2}$.

$\mathrm{Na}$ figura 3, verifica-se a eficiência fotoquímica potencial, avaliada pela relação $\mathrm{F}_{\mathrm{V}} / \mathrm{F}_{\mathrm{M}}$, ao longo do dia. Embora o mamoeiro seja uma planta de metabolismo $C_{3}$, com saturação por luz, e embora se tenha registrado valores de DFFF próximos de 1.900 $\mu \mathrm{mol} \mathrm{m} \mathrm{s}^{-1}$ e $2.400 \mu \mathrm{mol} \mathrm{m}^{-2} \mathrm{~s}^{-1}$, em outubro de 2002 e janeiro de 2003, respectivamente, observou-se que os valores da relação $\mathrm{F}_{\mathrm{V}} / \mathrm{F}_{\mathrm{M}}$, medida em folhas completamente expandidas e crescidas em pleno sol, mantiveram-se entre 0,78 e 0,83 .

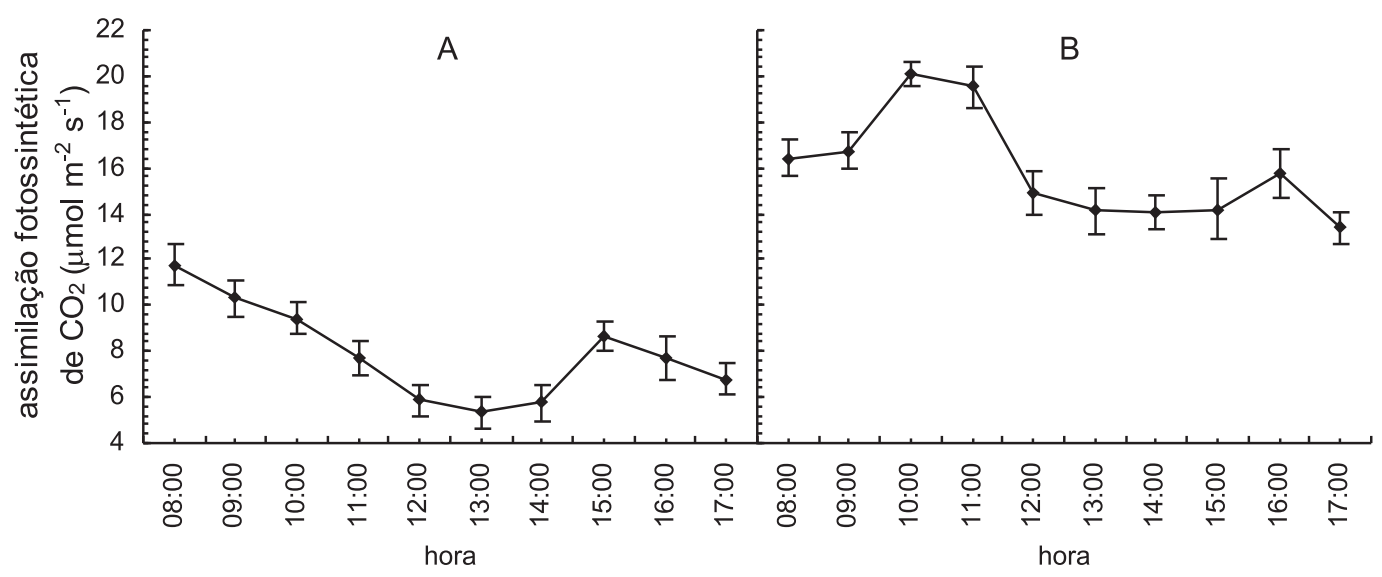

Figura 2. Variação da assimilação fotossintética de $\mathrm{CO}_{2}$ ao longo do dia em outubro de 2002 (A) e em janeiro de 2003

(B). As barras verticais indicam o erro-padrão. 
Segundo CRitchley (1998), em folhas de sol, os valores típicos dessa relação estão em torno de 0,8 ou um pouco abaixo de 0,8 . Em folhas de sombra, valores estão sempre entre 0,83 e 0,85 , com uma diferença em torno de $4 \%$. O autor relata que, em valores abaixo de 0,725 , as folhas certamente foram submetidas ao dano fotoinibitório. Embora em janeiro tenha havido uma queda do valor desta variável a partir de 8 até $11 \mathrm{~h}$, neste trabalho com mamoeiro em condição de campo, pode-se afirmar que as folhas das plantas não foram submetidas à fotoinibição, uma vez que os valores foram superiores ao relatado por CRITCHLEY (1998).

Os efeitos não-estomáticos, na maioria das vezes, são desencadeados por problemas fotoquímico/ bioquímicos, entretanto, comprometimentos no aparato fotossintético não foram detectados pela avaliação da eficiência fotoquímica potencial (Figura 3). De fato, em condição de campo, no horário mais quente do dia e em ambas as épocas estudadas, observou-se nas folhas do mamoeiro o fenômeno denominado paraeliotrópico (REIS, 2003), o qual pode ter minimizado os efeitos dos elevados valores de DFFF. Assim, torna-se justificável a ausência de fotoinibição nessa espécie, ao menos fotoinibição do tipo crônica. Esse movimento foliar denominado paraeliotrópico coincide, normalmente, com o fechamento estomático (LUDLOW e BJÖRKMAN, 1984), evidenciando que os efeitos estomáticos atuaram sobre a assimilação fotossintética de $\mathrm{CO}_{2}$ observada neste trabalho no Norte Fluminense.

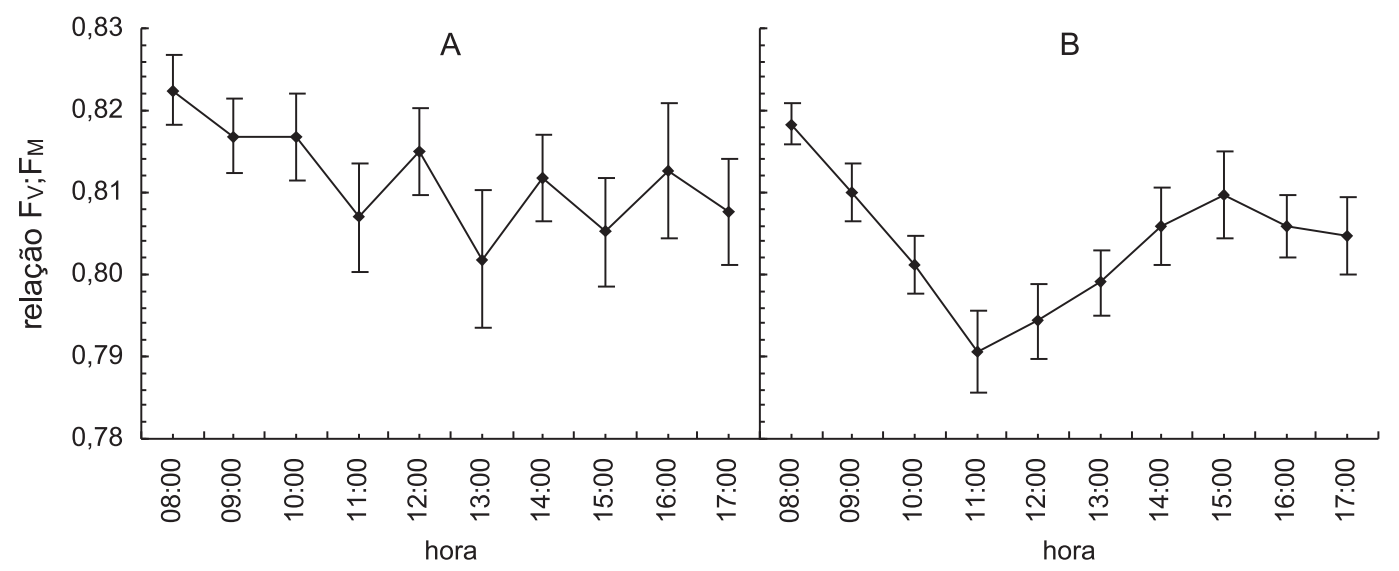

Figura 3. Variação da relação $F_{V} / F_{M}$ ao longo do dia em outubro de 2002 (A) e em janeiro de 2003 (B). As barras verticais indicam o erro-padrão.

Quando comparada a outubro, a assimilação fotossintética de $\mathrm{CO}_{2}$ foi maior em janeiro. Tal resultado foi devido à maior abertura estomática nas folhas das plantas cultivadas nesta época. A menor taxa fotossintética líquida em outubro, causada pela redução de $g_{S}$, foi decorrente da maior densidade de fluxo de fótons fotossintéticos (dias com ausência de nuvens) verificado em outubro.

Nas condições em estudo, por meio de medições da eficiência fotoquímica potencial, não foi verificado o efeito fotoinibitório do tipo crônico. É possível que esta não-detecção do dano ao aparato fotossintético tenha sido devido ao movimento paraeliotrópico das folhas, observado nos horários mais quentes do dia. Esses resultados podem contribuir significativamente no manejo da cultura do mamoeiro cultivado em condição de campo, uma vez que qualquer estratégia de manejo que possa otimizar a abertura estomática poderá trazer contribuições para a assimilação fotossintética de $\mathrm{CO}_{2} \mathrm{com}$ possibilidades de aumento de produtividade.

\section{REFERÊNCIAS}

BRUGNOLI, E.; BJÖRKMAN, O. Chloroplast movements in leaves: influence on chlorophyll fluorescence and measurements of light-induced absorbance Changes related to $\mathrm{pH}$ and zeaxanthin formation. Photosynthesis Research, New York, v.32, p.23-35, 1992.

CHAUMONT, M.; OSÓRIO, M.L.; CHAVES, M.M.; VANACKER, H.; MOROT-GAUDRY, J.-F.; FOYER, C.H. The absence of photoinhibition during the mid-morning depression of photosynthesis in Vitis vinifera grown in semiarid and temperate climates. Journal of Plant Physiology, Stuttgart, v.150, p.743-751, 1997.

CLEMENTE, H.S.; MARLER, T.E. Drought stress influences gas-exchange responses of papaya leaves to rapid changes in irradiance. Journal of the American Society for Horticultural Science, Alexandria, v. 12, n.2, p.292-295, 1996.

CRITCHLEY, C. Photoinhibition. In: RAGHAVENDRA, A.S. (Ed.). Photosynthesis: A comprehensive treatise. Cambridge: Cambridge University Press, 1998. p.264-272. 
CRITCHLEY, C.; RUSSELL, W. Photoinhibition of photosynthesis in vivo: the role of protein turnover in photosystem II. Physiologia Plantarum, New York, v.92, p.188196, 1994.

DEMMIG-ADAMS, B.; ADAMS W.W. III Photoprotection and other responses of plants to high light stress. Annual Review of Plant Physiology and Plant Molecular Biology, New York, v.43, p.599-626, 1992.

EL-SHARKAWY, M.A.; COCK, M.J.H. Water use efficiency of cassava. I. Effects of air humidity and water stress on stomatal conductance and gas exchange. Crop Science, Madison, v.24, p.497-502, 1984.

EL-SHARKAWY, M.A.; COCK, M.J.H.; HERNANDEZ, A.D.P. Stomatal response to air humidity and its relation to stomatal density in a wide range of warm climate species. Photosynthesis Research, New York, v. 7, p.137-149, 1985.

GAMON, J.A.; PEARCY, R.W. Leaf movement, stress avoidance and photosynthesis in Vitis califormica. Oecologia, New York, v.79, p.475-481, 1998 .

HUANG, L.F.; ZHENG, J.H.; ZHANG, Y.Y.; HU, W.H.; MAO, W.H.; ZHOU, Y.H.; YU, J.Q. Diurnal variations in gas exchange, chlorophyll fluorescence quenching and light allocation in soybean leaves: The cause for midday depression in $\mathrm{CO}_{2}$ assimilation. Scientia Horticulturae, Alexandria, v. 110, p.214218, 2006.

KAO, W.-Y.; FORSETH, I.N. Diurnal leaf movement, chlorophyll fluorescence and carbon assimilation in soybean grown under different nitrogen and water availabilities. Plant, Cell and Environment, Oxford, v.15, p.703-710, 1992.

LONG, S.P. $C_{4}$ photosynthesis at low temperatures. Plant, Cell and Environment, Oxford, v. 6, p.345-363, 1983.

LONG, S.P.; HUMPHRIES, S.; FALKOWSKI, P.G. Photoinhibition of photosynthesis in nature. Annual Review of Plant Physiology and Plant Molecular Biology, New York, v. 45, p.633-662, 1994.

LUDLOW, M.M.; BJÖRKMAN, O. Paraheliotropic leaf movement in siratro as a protective mechanism against drought-induced damage to primary Photosynthetic reactions: damage by excessive light and heat. Planta, Heidelberg, v. 161, p.505-518, 1984.

MACHADO-FILHO, J.A.; CAMPOSTRINI, E; YAMANISHI, O.K.; FAGUNDES, G.R. Efeito da umidade do ar nas trocas gasosas em folhas de mamoeiro (Carica papaya L.) cultivado em condições de campo. Bragantia, Campinas, v. 65, p.185196, 2006.

MALO, S.E.; CAMPBELL, C.W. The papaya. Gainesville: University of Florida, Florida Cooperative Extension Service, 1986. (Fruits Crops Fact Sheet FC-11)
MARLER, T.E.; MICKELBART, M.V. Drought, leaf gas exchange, and chlorophyll fluorescence of field grown papaya. Journal of the American Society of the Horticultural Science, Alexandria, v. 123, n.4, p.714-718, 1998.

MONTEITH, J.L. A reinterpretation of stomatal responses to humidity. Plant, Cell and Environment, Oxford, v. 18, p.357364, 1995.

MAIER-MAERCKER, U. The role of peristomatal transpiration in the mechanism of stomatal movement. Plant, Cell and Environment, Oxford, v. 6, p.369-380, 1983.

ÖGREEN, E. Photoinhibition of photosynthesis in willow leaves under field conditions. Planta, Heidelberg, v. 175, p.229236, 1988.

ÖGREEN, E. The significance of photoinhibition for photosynthetic productivity. In: BAKER, N.R.; BOWYER, J.R. (Eds.). Photoinhibition of photosynthesis from molecular mechanisms to the field. Oxoford, UK: BIOS Science Publishers, 1994. p.433-447.

PEARCY, R.W. Acclimation on sun and shade. In: Raghavendra, A.S. (Ed.). Photosynthesis - A comprehensive treatise. Cambridge: Cambridge University Press, 1998. p.250-263.

POWLES, S.B.; CRICHLEY, C. Effect of light intensity during growth on photoinhibition of intact attached bean leaflets. Plant Physiology, Rockville, v. 65, p.1181-1187, 1980.

RASCHKE, K.; RESEMANN, A. The midday depression of $\mathrm{CO}_{2}$ assimilation in leaves of Arbutus unedo L.: diurnal changes in photosynthetic capacity related to changes in temperature and humididy. Planta, Heidelberg, v. 168, p.546-558, 1986.

REIS, F.O. Trocas gasosas, eficiência fotoquímica e fluxo de seiva xilemática em mamoeiro do grupo 'Formosa' cultivado em condição de campo na região Norte Fluminense. Dissertação (Mestrado em Produção Vegetal) - Universidade Estadual do Norte Fluminense (UENF), Campos dos Goytacazes, 2003.

REIS, F.O., Microaspersão sobrecopa em mamoeiro 'Golden': um estudo relacionado às trocas gasosas, à eficiência fotoquímica e ao fluxo de seiva xilemática. Tese (Doutorado em Produção Vegetal) - Universidade Estadual do Norte Fluminense (UENF), Campos dos Goytacazes, 2007.

ROBINSON, S.A.; LOVELOCK, C.E., OSMOND, C.B. Wax as a mechanism for protection against photoinhibition - a study of Cotyledon orbiculata. Botanica Acta, New York, v. 106, n.4, p.307-312, 1993.

SALAZAR, R. Determination of photosynthesis in commercial varieties of papaw (Carica papaya L.) and its possible relationship with the production and quality of the fruits. Revista ICA, Bogota, v.2, n.13, p.291-295, 1978. 
SU, P.; LIU, X. Photosynthetic characteristics of linze jujube in conditions of high temperature and irradiation. Scientia Horticulturae, Alexandria, v. 104, n.3, p.339-350, 2005.

TORRES-NETTO, A.; CAMPOSTRINI, E.; OLIVEIRA, J.G.; YAMANISHI, O.K. Portable chlorophyll meter for the quantification of photosynthetic pigments, nitrogen and the possible use for assessment of the photochemical process in Carica papaya L. Brazilian Journal of Plant Physiology, Campinas, v. 14, n.3, p.203-210, 2002.

XU, D.; SHEN Y. Midday depression of Photosynthesis. In: PESSARAKLI, M. (Ed.). Handbook of photosynthesis. New York: Marcel Dekker, Inc. 1997. p.451-459. 